\title{
RELIGIÃO E POLÍTICA: MEDOS SOCIAIS, EXTREMISMO RELIGIOSO E AS ELEIÇÕES
}

\author{
Fermanda Marina Feitosa Coelho*
}

VITAL DA CUNHA, Cristina; LOPES, Paulo Victor Leite; LUI, Janayna. Religião e Política: medos sociais, extremismo religioso e as eleições 2014. Rio de Janeiro: Fundação Henrich Böll, 2017, 196p.

O livro Religião e Política: medos sociais, extremismo religioso e as eleições 2014, desenvolvido pelo Instituto de Estudos de Religião (ISER) em parceria com a Fundação Henrich Böll (HBS), retoma diligentemente as relações entre política e religião no Brasil contemporâneo e surge como continuidade de outra obra escrita por Cristina Vital da Cunha e Paulo Victor Leite Lopes, intitulada Religião e Política: uma análise da atuação de parlamentares evangélicos sobre direitos das mulheres e de LGBTs no Brasil. Se neste primeiro livro o destaque foi dado para a atuação de parlamentares evangélicos na obstaculização de direitos da população LGBT e das mulheres, a temática ainda perpassa a presente obra, que analisa de forma específica o contexto das eleições de 2014, demonstrando a complementariedade entre esta e a obra que a precede. Nessa continuidade, Cristina Vital da Cunha, Paulo Victor Leite Lopes e Janayna Lui analisam as candidaturas do Pastor Everaldo (PSC), de Marcelo Crivella (PRB) e de Anthony Garotinho (PR) com o intuito de compreender o posicionamento recente de políticos religiosos e seus lugares na política brasileira contemporânea. Por todo o livro, perpassa a noção da permanente construção da democracia. Assim, a obra

* Doutoranda do Programa de Pós-Graduação em Ciências da Religião na Universidade Metodista de São Paulo, na área de Religião, Sociedade e Cultura, com pesquisa específica sobre Gênero, Política e Religião (Bolsista CNPq). Membro do Grupo de Pesquisa em Gênero e Religião Mandrágora/NETMAL. Endereço eletrônico: femfcoelho@gmail.com 
intensifica a importância da discussão e reflexão sobre a política e o mundo político no país.

O Capítulo 1 do livro, Um pastor candidato: a primeira candidatura confessional evangélica à Presidência do Brasil, demonstra o objetivo do Partido Social Cristão (PSC) em "se fortalecer junto ao eleitorado conservador, de um modo geral, e ao eleitorado evangélico, em particular" (p. 18) com a candidatura do Pastor Everaldo, que contava com aproximadamente $4 \%$ das intenções de voto. O capítulo dispõe uma breve biografia e trajetória do Pastor, até o momento em que se filiou ao PSC. Ainda, estabelece sua relação com o deputado federal Eduardo Cunha (PMDB-RJ). A participação de Everaldo no PSC acrescentou força à legenda, aumentando expressivamente o número de suas cadeiras na Câmara dos Deputados. Posteriormente, o capítulo analisa o jogo político-religioso quando explana a luta do Pastor Everaldo contra Dilma Rousseff nas pré-candidaturas de 2013, em oposição ao seu apoio a essa candidata em 2010. Mesmo com o apoio do então presidente da Comissão de Direitos Humanos da Câmara, deputado federal Marco Feliciano (PSC-SP), Pastor Everaldo não atraiu o número esperado de votos de evangélicos. Entretanto, a aliança foi usada para reforçar a perspectiva partidária contra a habilidade política da presidente Dilma Rousseff e, por conseguinte, contra as políticas sociais que faziam parte do projeto político do Partido dos Trabalhadores.

Tal contrariedade em relação às políticas sociais e ao movimento sindical, do qual o Partido dos Trabalhadores é fruto, já havia sido identificada por Prandi \& Mariano (1996) como uma característica do eleitorado evangélico desde as eleições que fizeram de Collor de Melo presidente, conforme aponta o texto. Assim, a utilização de um projeto político notadamente liberal em termos econômicos, com claro apoio às privatizações e combatente das políticas sociais, marcou a campanha do Pastor Everaldo por reverberar no "senso comum" evangélico. De acordo com os autores, a definição da candidatura do Pastor Everaldo à Presidência da República foi tratada pela mídia como algo que objetivava a construção de um "bloco evangélico" que pudesse aglutinar os votos desse grupo de forma a atender aos seus interesses político-religiosos. Embora Pastor Everaldo tenha rebatido tais afirmações, é importante 
considerar que, enquanto em relação à população geral, sua candidatura representava $4 \%$ das intenções de voto, entre os evangélicos esse número subia para $11 \%$.

Apesar dos esforços do Pastor Everaldo em descentrar sua campanha do campo religioso, o texto revela que sua estratégia partidária foi marcada por atividades relacionadas a igrejas e eventos religiosos evangélicos, visto que o candidato carecia de apoio político na maior parte dos estados brasileiros. Ainda assim, o Pastor, reconhecido como o primeiro candidato evangélico à Presidência da República, obteve apoio de diversas lideranças nacionais pentecostais evangélicas, com destaque para Robson Rodovalho, Silas Malafaia, Magno Malta, Marco Feliciano, Manoel Ferreira e Mário de Oliveira.

O segundo capítulo, Estratégias de poder e a apresentação de um perfil liberal conservador religioso, inicia expondo a verdadeira mudança como mote da campanha do Pastor Everaldo e discorre sobre o plano de governo do candidato que, em suma, era composto por três princípios civilizatórios consagrados, quais sejam, qualidade de vida, poder nacional e governança, que podiam ser traduzidos nas bandeiras contra a legalização do aborto e na defesa da família tradicional, principalmente para jovens. Dentre suas pautas morais, contavam também o combate à corrupção e ao tráfico de drogas. Apelando para leituras neoliberais de princípios cristãos que enfatizam valores conhecidos pela sociedade como a meritocracia associada à ideia de que "com o suor do teu rosto comerás o pão" (p. 53), seu programa de governo alcançou maior visibilidade midiática. Em contrapartida, o Pastor contrapunha-se ao casamento igualitário, revelando seu posicionamento excludente e deslegitimador de demandas sociais de grupos não hegemônicos. O capítulo ainda aborda as diferenças de uso da linguagem política e religiosa nos diferentes espaços públicos utilizados para alavancar sua campanha, a saber, entrevistas coletivas, debates eleitorais na televisão, postagens nas mídias sociais, nas comunidades religiosas, dentre outros.

A campanha do Pastor Everaldo enfrentou desafios, ambos advindos de seu compromisso com a moral religiosa. Por um lado, a desconfiança dos liberais e, por outro, o descontentamento da imprensa com a falta de aprofundamento em seu discurso e o constante apelo à ban- 
deira da família tradicional, denunciando o caráter liberal estritamente econômico de sua campanha. Tal contradição, mormente, caracteriza o perfil do candidato como liberal conservador religioso. Outro grande desafio enfrentado por Pastor Everaldo se deu em decorrência do falecimento de Eduardo Campos (PSB) e a nomeação da nova candidata do partido, a Senadora Marina Silva (PSB), evento que diminuiu seu capital político-religioso como o único candidato evangélico na corrida presidencial e que lhe custou o apoio de proeminentes lideranças religiosas e, consequentemente, de votos evangélicos. Ainda que esse capital religioso de Marina Silva e Pastor Everaldo fosse reafirmado em muitos momentos, a exploração de sua identidade gerou rejeição política por parte de setores simpatizantes da defesa e ampliação dos direitos de minorias até o fim do primeiro turno das eleições presidenciais de 2014.

O capítulo finda com breve análise do segundo turno, em que Pastor Everaldo (PSC) declara apoio ao candidato Aécio Neves (PSDB). Embora Pastor Everaldo justificasse seu apoio com um crescimento da corrupção durante o governo Dilma, o texto aponta a concorrente como reconhecida defensora de minorias sociais, contexto que denotaria a clara contrariedade à moral cristã defendida pelo próprio ex-candidato durante o primeiro turno.

A partir de pesquisa anterior (Cristina VITAL DA CUNHA; Paulo Victor Leite LOPES, 2012), Vital da Cunha, Lopes e Lui (2017) analisam as eleições para governador do Estado do Rio de Janeiro em 2014 no Capítulo 3, intitulado Agenciamentos em torno do religioso: a eleição para governador do Rio de Janeiro em 2014, a fim de evidenciar a singularidade dos jogos políticos envolvidos nesse pleito e de trazer à tona as relações entre religião e política que não se evidenciam em âmbito nacional. Para tanto, o texto oferece um panorama geral acerca dos candidatos, seus históricos políticos, partidos e campanhas, bem como de suas buscas por apoio e coligações com outros partidos. Ainda, expõe articulações com a corrida presidencial realizada por Dilma Rousseff (PT), que buscava apoio dos quatro principais pré-candidatos para se reeleger. Os dois candidatos evangélicos do grupo, Anthony Garotinho (PR), da Igreja Presbiteriana e Marcelo Crivella (PRB), da Igreja Universal do Reino de Deus protagonizaram uma disputa político-religiosa distinta no pleito, 
chegando a envolver o candidato Lindbergh Farias (PT), reconhecido por defender posicionamentos não condizentes com a moral cristã, na disputa pelo apoio evangélico. De acordo com os autores, tal episódio revela diferentes estratégias por parte dos candidatos com relação aos seus pertencimentos religiosos e das formas como apelam para a linguagem religiosa em suas campanhas.

O segundo turno trouxe o candidato Pezão (PMDB) ao centro dos confrontos da relação entre religião e política. A estratégia de sua campanha foi a de desconstruir a imagem de Crivella (PRB), seu adversário, a partir de sua vinculação com Edir Macedo, principal líder da Igreja Universal do Reino de Deus, e também seu tio. A partir desse vínculo, os autores discutem a relação entre política, religião e dinheiro. $O$ apoio do terceiro e quarto colocados no primeiro turno, respectivamente Garotinho (PR) e Lindbergh (PT), a Crivella (PRB) acirraram o embate. O capítulo finaliza explicitando as acusações que Crivella (PRB) sofreu nesse contexto.

Conclusão: Reavaliando categorias sociais - como pensar os evangélicos na sociedade e na política no Brasil contemporâneo é o título do Capítulo 4, que expressa a perspectiva dos autores em relação aos assuntos tratados no decorrer da obra. Nele, os autores refletem sobre períodos de transformação social, medos sociais, pânico moral e tradição. Em meio às disputas sociais pelo poder, os autores se empenham em encontrar denominadores comuns para as ações de sujeitos evangélicos na política, ainda que destaquem sua pluralidade. Assim, o livro dispõe três tipos de ações, quais sejam, extremistas, conservadoras e progressistas.

Ao diferenciar o fundamentalismo evangélico atual do fundamentalismo histórico cristão, os autores negam uma equivalência entre fundamentalismo e violência. Dessa maneira, caracterizam como ações extremistas aquelas em que ocorre a manipulação de uma perspectiva fundamentalista que, por vezes, utiliza a violência material e por outras a incita, necessariamente associando esta a uma orientação moral. Ainda, há destaque para conluios políticos, posicionamentos radicais, imposição de valores e obstaculização dos direitos de minorias. As ações conservadoras, por sua vez, distinguiram-se por resistência à mudança ou por omissão à violência contida nas ações extremistas. Por fim, as ações progressistas têm caráter crítico, posicionando-se politicamente 
a favor dos direitos humanos das chamadas minorias. Para além desta discussão, o texto ainda retoma o perfil liberal-conservador para analisar o papel dos evangélicos na política nacional, caracterizando-os como players, por meio de seu fortalecimento e da defesa da bandeira da família, por intermédio da religião ou da tradição.

O livro ainda conta com uma sessão extra sobre Religião, direitos e liberdades laicas no Brasil contemporâneo e abarca dois trabalhos. O conteúdo compreende o tema mais geral da religião no espaço público brasileiro na atualidade, com a participação de interlocutoras do ISER. O primeiro trabalho, "É preciso salvar a família": gênero, religião e política no contexto do neoconservadorismo evangélico nas mídias no Brasil, escrito por Magali do Nascimento Cunha, demonstra a forma como a mídia é usada por celebridades para disseminar o neoconservadorismo evangélico por meio de seu acesso ao público evangélico e da pregação da moralidade religiosa conservadora em relação às sexualidades e ao corpo da mulher, adentrando o espaço político. Em seguida, A militância política de grupos ecumênicos na construção da democracia brasileira, por Tatiane dos Santos Duarte, analisa a participação política do movimento ecumênico na contestação da religião promotora de ódios e discriminações no espaço público e na forma como advoga pela legitimidade da articulação entre suas crenças e valores modernos/seculares.

O livro Religião e Política: medos sociais, extremismo religioso e as eleições 2014 amplia novas perspectivas para o entendimento do lugar político dos evangélicos no Brasil contemporâneo. Cristina Vital da Cunha, Paulo Victor Leite Lopes e Janayna Lui demonstram como a busca política por um governo dos mais fortes é realizada com a construção de uma democracia representativa, que nega a representatividade social pela afirmação de uma democracia restrita ao poder político, conformado como nova direita, orquestrado para abranger posicionamentos de políticos religiosos e não religiosos. Destarte, a presente obra reitera, mais uma vez, a inesgotável importância dos debates que articulam religião e política no Brasil, demonstrando as formas pelas quais a religião tem sido parte componente de processos e decisões políticas fundamentais à vida de todas as cidadãs e todos os cidadãos, e não somente de uma minoria social que se posiciona estrategicamente como maioria política. 